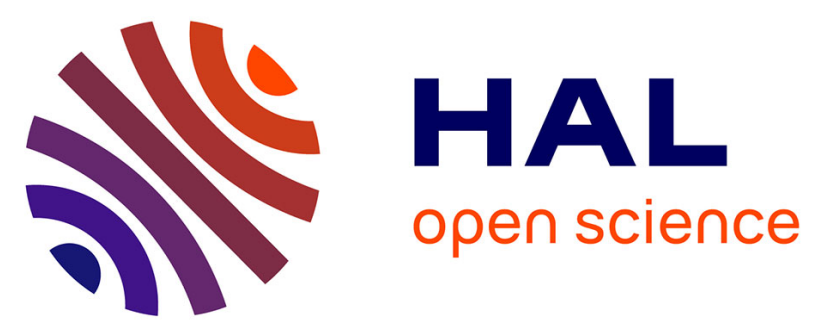

\title{
Pathogenic FBN1 mutations in 146 adults not meeting clinical diagnostic criteria for Marfan syndrome: Further delineation of type 1 fibrillinopathies and focus on patients with an isolated major criterion
}

G Faivre, Gwenaëlle Collod-Béroud, C Callewaert, C Child, L. Loeys, C. Binquet, E. Gautier, A Arbustini, M. Mayer, A Arslan-Kirchner, et al.

\section{To cite this version:}

G Faivre, Gwenaëlle Collod-Béroud, C Callewaert, C Child, L. Loeys, et al.. Pathogenic FBN1 mutations in 146 adults not meeting clinical diagnostic criteria for Marfan syndrome: Further delineation of type 1 fibrillinopathies and focus on patients with an isolated major criterion. American Journal of Medical Genetics Part A, 2009, 149A (5), pp.854 - 860. 10.1002/ajmg.a.32809 . hal-01669908

\section{HAL Id: hal-01669908 https://hal.science/hal-01669908}

Submitted on 21 Dec 2017

HAL is a multi-disciplinary open access archive for the deposit and dissemination of scientific research documents, whether they are published or not. The documents may come from teaching and research institutions in France or abroad, or from public or private research centers.
L'archive ouverte pluridisciplinaire HAL, est destinée au dépôt et à la diffusion de documents scientifiques de niveau recherche, publiés ou non, émanant des établissements d'enseignement et de recherche français ou étrangers, des laboratoires publics ou privés. 


\section{Pathogenic FBN1 Mutations in 146 Adults Not Meeting Clinical Diagnostic Criteria for Marfan Syndrome: Further Delineation of Type 1 Fibrillinopathies and Focus on Patients With an Isolated Major Criterion}
L. Faivre, ${ }^{1,2 *}$
G. Collod-Beroud, ${ }^{3,4}$
B. Callewaert, ${ }^{5}$
A. Child, ${ }^{6}$ B.L. Loeys, ${ }^{5,7}$
C. Binquet, ${ }^{2,8}$
E. Gautier, ${ }^{2,8}$
E. Arbustini, ${ }^{9} \mathrm{~K}$
K. Mayer, ${ }^{10}$ M. Arsla
-Kirchner, ${ }^{11} A$
C. Beroud, ${ }^{3,4,12}$
C. Bonithon-Kopp,
M. Claustres,
Kiotse
C. Stheneur, ${ }^{13,14}$
P.N. Robinson, ${ }^{17}$ L. Adès, ${ }^{18,19}$
C. Boileau, ${ }^{14,2}$
$14,22,23$
and G. Jondeau ${ }^{23}$

${ }^{1}$ Centre de Génétique, CHU Dijon, Dijon, France

${ }^{2}$ Centre d'Investigation Clinique-Épidémiologie Clinique/Essais Cliniques, CHU Dijon, Dijon, France

${ }^{3}$ INSERM, U827, Montpellier, France

${ }^{4}$ Université Montpellier I, Montpellier, France

${ }^{5}$ Center for Medical Genetics, Ghent University Hospital, Ghent, Belgium

${ }^{6}$ Department of Cardiological Sciences, St. George's Hospital, London, UK

'Institute of Genetic Medicine, Howard Hughes Medical Institute, Johns Hopkins University School of Medicine, Baltimore, Maryland

${ }^{8}$ Inserm, CIE1, Dijon, France

${ }^{9}$ Centre for Inherited Cardiovascular Diseases, Foundation IRCCS Policlinico San Matteo, Pavia, Italy

${ }^{10}$ Center for Human Genetics and Laboratory Medicine, Martinsried, Germany

${ }^{11}$ Institut für Humangenetik, Hannover, Germany

${ }^{12} \mathrm{CHU}$ Montpellier, Hôpital Arnault de Villeneuve, Laboratoire de Génétique Moléculaire, Montpellier, France

${ }^{13}$ AP-HP, Hôpital Ambroise Paré, Service de Pédiatrie, Boulogne, France

${ }^{14}$ Université Versailles-Saint Quentin en Yvelines, UFR P.I.F.O., Garches, France

${ }^{15}$ Chirurgie Cardiovasculaire, CHU le Bocage, Dijon, France

${ }^{16}$ Cardiologie, CHU, Dijon, France

${ }^{17}$ Institut für Medizinische Genetik, Universitätsmedizin Charité, Berlin, Germany

${ }^{18}$ Marfan Research Group, The Children's Hospital at Westmead, Sydney, Australia

${ }^{19}$ Discipline of Paediatrics and Child Health, University of Sydney, Sydney, Australia

${ }^{20}$ Department of Clinical Genetics, The Children's Hospital at Westmead, Sydney, Australia

${ }^{21}$ Departments of Genetics and Pediatrics, Stanford University Medical Center, Stanford, California

${ }^{22}$ AP-HP, Hôpital Ambroise Paré, Laboratoire de Génétique Moléculaire, Boulogne, France

${ }^{23}$ AP-HP, Hôpital Bichat, Consultation Pluridisciplinaire Marfan, Paris, France

Grant sponsor: French Ministry of Health; Grant sponsor: GIS-Maladies

Rares and ANR-Maladies Rares 2005.

${ }^{\star}$ Correspondence to:

L. Faivre, Centre de Génétique, Hôpital d’Enfants, 10, bd Maréchal

DeLattre de Tassigny, 21034 Dijon, France.

E-mail: laurence.faivre@chu-dijon.fr 
Mutations in the FBN1 gene cause Marfan syndrome (MFS) and have been associated with a wide range of milder overlapping phenotypes. A proportion of patients carrying a FBN1 mutation does not meet diagnostic criteria for MFS, and are diagnosed with "other type I fibrillinopathy." In order to better describe this entity, we analyzed a subgroup of 146 out of 689 adult propositi with incomplete "clinical" international criteria (Ghent nosology) from a large collaborative international study including 1,009 propositi with a pathogenic FBN1 mutation. We focused on patients with only one major clinical criterion, [including isolated ectopia lentis (EL; 12 patients), isolated ascending aortic dilatation (17 patients), and isolated major skeletal manifestations (1 patient)] or with no major criterion but only minor criteria in 1 or more organ systems (16 patients). At least one component of the Ghent nosology, insufficient alone to make a minor criterion, was found in the majority of patients with isolated ascending aortic dilatation and isolated EL. In patients with isolated EL, missense mutations involving a cysteine were predominant, mutations in exons 24-32 were underrepresented, and no mutations leading to a premature truncation were found. Studies of recurrent mutations and affected family members of propositi with only one major clinical criterion argue for a clinical continuum between such phenotypes and classical MFS. Using strict definitions, we conclude that patients with FBN1 mutation and only one major clinical criterion or with only minor clinical criteria of one or more organ system do exist but represent only $5 \%$ of the adult cohort.

Key words: type I fibrillinopathy; FBN1 gene; Marfan syndrome; international criteria

\section{INTRODUCTION}

Marfan syndrome (MFS; OMIM 154700) is a connective tissue disorder, with autosomal dominant inheritance and a prevalence of 1/5,000-10,000 individuals [Pyeritz, 1993]. The cardinal features of MFS involve the ocular, cardiovascular and skeletal systems [Judge and Dietz, 2005]. The skin, lung, and dura may also be involved. Because of the high population frequency and the nonspecific nature of many of the clinical findings in MFS, clinical diagnostic criteria for this disorder have been established [De Paepe et al., 1996]. MFS is notable for variability in the timing of onset, tissue distribution and severity of clinical manifestations, both between and within affected families. Following the identification of fibrillin-1 (FBN1) gene mutations in MFS [Dietz et al., 1991], a growing list of related phenotypes that do not fulfill the international criteria for MFS has been associated with FBN1 mutations and led to the use of the descriptive term "type I fibrillinopathies" [Furthmayr and Francke, 1997; Robinson et al., 2002, 2006; Boileau et al., 2005]. In particular, patients with only one major criterion have been described, including isolated ectopia lentis (EL; OMIM 129600) [Kainulainen et al., 1994; Lönnqvist et al., 1994], isolated ascending aortic aneurysm and/or dissection (AAD) [Francke et al., 1995; Milewicz et al., 1996], and isolated skeletal features [Hayward et al., 1994; Milewicz et al., 1995; Adès et al., 2002]. Highly variable definitions are found in the literature depending on the authors,

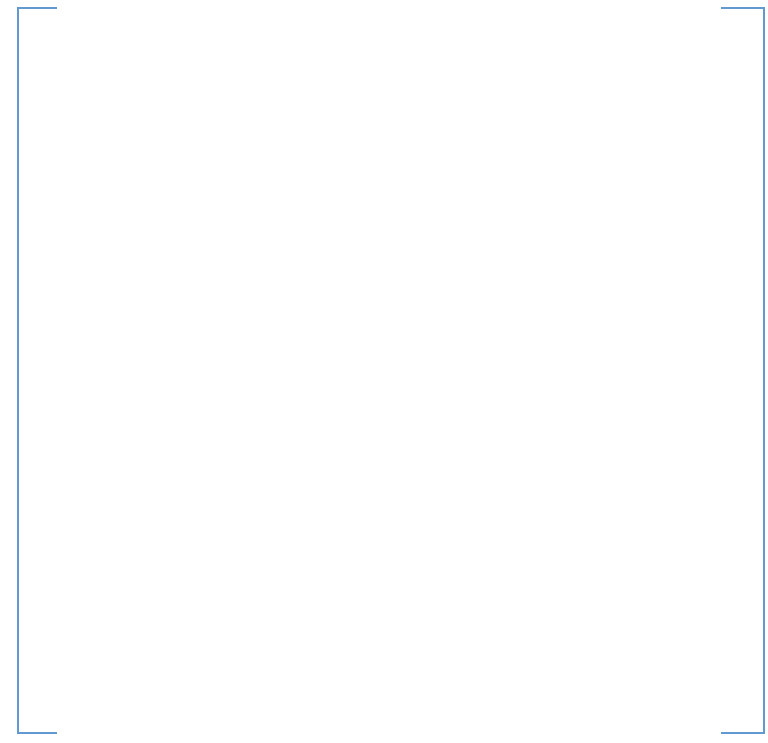

some of them accepting the existence of one or more minor criteria of another system [Comeglio et al., 2002; Adès et al., 2004]. The proportion of such mild phenotypes in the spectrum of FBN1 mutations remains unknown. Here we describe the clinical and molecular characteristics of 146 adult propositi not fulfilling the international criteria for MFS (Ghent nosology) and we particularly focus on patients with only one major clinical criterion as well as patients with only minor criteria out of a series of 1,009 propositi with a known FBN1 mutation.

\section{PATIENTS, MATERIALS, AND METHODS}

Patients were initially recruited for a genotype-phenotype correlation study [Faivre et al., 2007], during the period 1995-2005 via the framework of the Universal Marfan database-FBN1 (UMDFBN1; http:/www.umd.be) [Collod-Beroud et al., 2003], or were referred by specialized MFS clinics in their respective countries. Patients originated from 38 countries on the 5 continents. The clinical information collected included a range of qualitative and quantitative clinical parameters, including age of diagnosis, presence or absence of clinical features including cardiac, ophthalmological, skeletal, skin, lung, and dura manifestations of the Ghent nosology [De Paepe et al., 1996; Faivre et al., 2007]. The number of systems clinically involved was assessed according to the international nosology that recognizes six organ systems.

The words criteria, minor and major criteria, organ system component are strictly used throughout the article as listed in the article by De Paepe et al. [1996] that defines the Ghent diagnostic criteria for MFS. The presence of one or several component(s) of one organ system may be insufficient alone to make a minor criterion, such as the presence of arachnodactyly and joint hyperlaxity alone in the skeletal system, for example. Isolated EL was defined by the presence of EL without any other major or minor criterion in another organ system. Similarly, isolated AAD and isolated major skeletal system affected were defined by the absence of any other major or minor criterion in another organ system.

Out of a series of 1,009 propositi including 689 adults carrying a pathogenic FBN1 mutation, we extracted data for 146 adult 
propositi not fulfilling the clinical international criteria (i.e., patients who did not fulfill Ghent criteria without taking into account the presence of a FBN1 gene mutation) in order to reproduce better the situation that clinicians face in their clinical practice. The phenotypes and the genotypes of the overall cohort of patients were described elsewhere [Faivre et al., 2007]. Only patients aged 18 or more were included in the present study in order to reduce the bias induced by the disease evolution over time. Within this subgroup, some propositi presented with only one major clinical criterion and others with only minor criteria according to Ghent nosology.

The genotype of these patients was compared to the genotype of the overall cohort. The pathogenic nature of a putative mutation was assessed using recognized criteria. In brief, all nonsense mutations, all deletions or insertions (in or out of frame) were considered pathogenic; for all splice mutations the wild-type and mutant strength values of the splice sites were compared using genetic algorithms [Shapiro and Senapathy, 1987; Dietz and Pyeritz, 1995; Beroud et al., 2005] and only mutations displaying significant deviation from the normal were included. Missense mutations were considered pathogenic when at least one of the following features was found: (i) de novo missense mutation, (ii) missense mutation substituting or creating a cysteine, (iii) missense mutation involving a consensus calcium-binding residue [Dietz and Pyeritz, 1995], (iv) substitution of glycines implicated in correct domain-domain packing [Downing et al., 1996], (v) intrafamilial segregation of a missense mutation involving a conserved amino acid. For other missense mutations not displaying one of the above features, additional data provided by SIFT [ $\mathrm{Ng}$ and Henikoff, 2001, 2003], BLOSUM-62 [Henikoff and Henikoff, 1992] and biochemical value (http://www.biochem218.stanford.edu/ Projects\%202001/Yu.pdf) were gathered and analyzed using a new UMD tool [Collod-Beroud, unpublished work].

Family members of a propositus with only one major criterion in a given organ system were studied when available in order to determine the range of intrafamilial phenotypic variability in this population with mild phenotypes.

\section{RESULTS}

Figure 1 shows the distribution of organ system involvement in patients not fulfilling international clinical criteria for MFS. Their median age at diagnosis was 28.5 years [IQR 20;42], which is not different from the median age at diagnosis in the population of adults fulfilling Ghent criteria (30 years [IQR 19;38]) [Faivre et al., 2007]. Forty-two patients had a positive family history (29\%). Only $27 / 146$ patients were investigated for dural ectasia. Thirty out of 146 patients presented with only one major clinical criterion, with or without family history, including isolated AAD (17/146, 12\%), isolated EL (12/146, 8\%) and isolated major skeletal manifestations $(1 / 146,1 \%)$. Their median age at diagnosis was 37 years [IQR 27;45]. Actually, 12/17 patients with an isolated AAD and 9/12 patients with isolated EL had one to 3 components of the skeletal system but their nature or their combinations do not meet the requirements of the Ghent nosology to define a skeletal criterion. This illustrates our strict use of the nosology. If we apply less stringent definitions to our cohort, the number of patients with isolated AAD can vary from 17 patients, 11 with family history, 6 without (and no associated minor criterion) to 63 patients (up to 3 organ systems presenting minor criteria) (Fig. 1). Similarly, the number of patients with isolated EL can vary from 12 patients, 10 with a family history, 2 without (and no associated minor criterion) to 29 patients (up to 3 organ systems presenting minor criteria) (Fig. 1). Within the 17 patients with isolated AAD, 11 had surgery for AAD and 4 had surgery for dissection of the ascending aorta. Of note, if the presence of the FBN1 mutation was considered as a major feature, $80 / 146(55 \%)$ patients could be reclassified as fulfilling Ghent criteria.

When considering the 16 adult propositi with no major criterion but 1-3 minor criteria (Fig. 1), 2 patients had 3 different organ systems affected (skeletal + cardiovascular + skin system minor criteria); 8 patients had 2 organ systems affected (3/8 had skeletal + cardiovascular minor criteria, $3 / 8$ skeletal + skin minor criteria, and 2/8 skeletal + lung minor criteria); 5 patients had a single system affected (4 patients had skeletal minor criteria, 1 patient who had joint hypermobility and had undergone surgery for aortic insufficiency, also had a skin criterion); and 1 patient had no minor nor major criterion. When examined at the age of 20 years, this individual had tall stature, arachnodactyly and atypical cardiovascular features (mitral insufficiency and atrial septal defect). None of these patients had a positive family history.

Table I reports the distribution of types and mutations in the groups of propositi with isolated EL or AAD without involvement of any other system, as well as patients with EL or AAD with at least one minor criterion in another organ system and patients with no major criterion. These results were compared with the total group of patients with type I fibrillinopathy and the overall population of propositi [Faivre et al., 2007]. Although the small size of the samples did not permit any statistical comparison, it is worth noting that no premature truncation (PTC) was found in the group of patients with isolated EL. Missense mutations involving a cysteine were overrepresented, 50\% creating and 50\% substituting a cysteine. This group was also characterized by an under-representation of mutations in exons 24-32 and overrepresentation of mutations at the $5^{\prime}$ end of the gene. The same tendency was found in patients with $\mathrm{EL}$ and at least one minor criterion in another organ system. No specific type or location of mutations could be found in the other groups of patients.

Inter- and intrafamilial variability provided further evidence for the range of phenotypic variation associated with FBN1 mutations. Indeed, two recurrent missense mutations were found in patients with isolated EL (c.718C $>\mathrm{T}$ and c.2722T $>\mathrm{C}$ ). The c.718C $>\mathrm{T}$ mutation was present in two adult propositi with isolated EL aged 64 and 42 years; it was also found in two adult propositi fulfilling the international diagnostic criteria, including one with aortic manifestations (EL, AAD, mitral regurgitation, and minor skeletal involvement in the overall series of 1,009 propositi [Faivre et al., 2007]). It was also present in a 13 -year-old child with isolated EL but who might develop other features later in life. Similarly, the c.2722T $>$ C mutation was found in two adult propositi with isolated EL and in a 34-year-old male with EL and AAD that required surgery. Information regarding 9 affected relatives of 3 adult propositi with isolated EL was available; 6/9 presented EL which was isolated in 2 of them. Information regarding 11 affected 


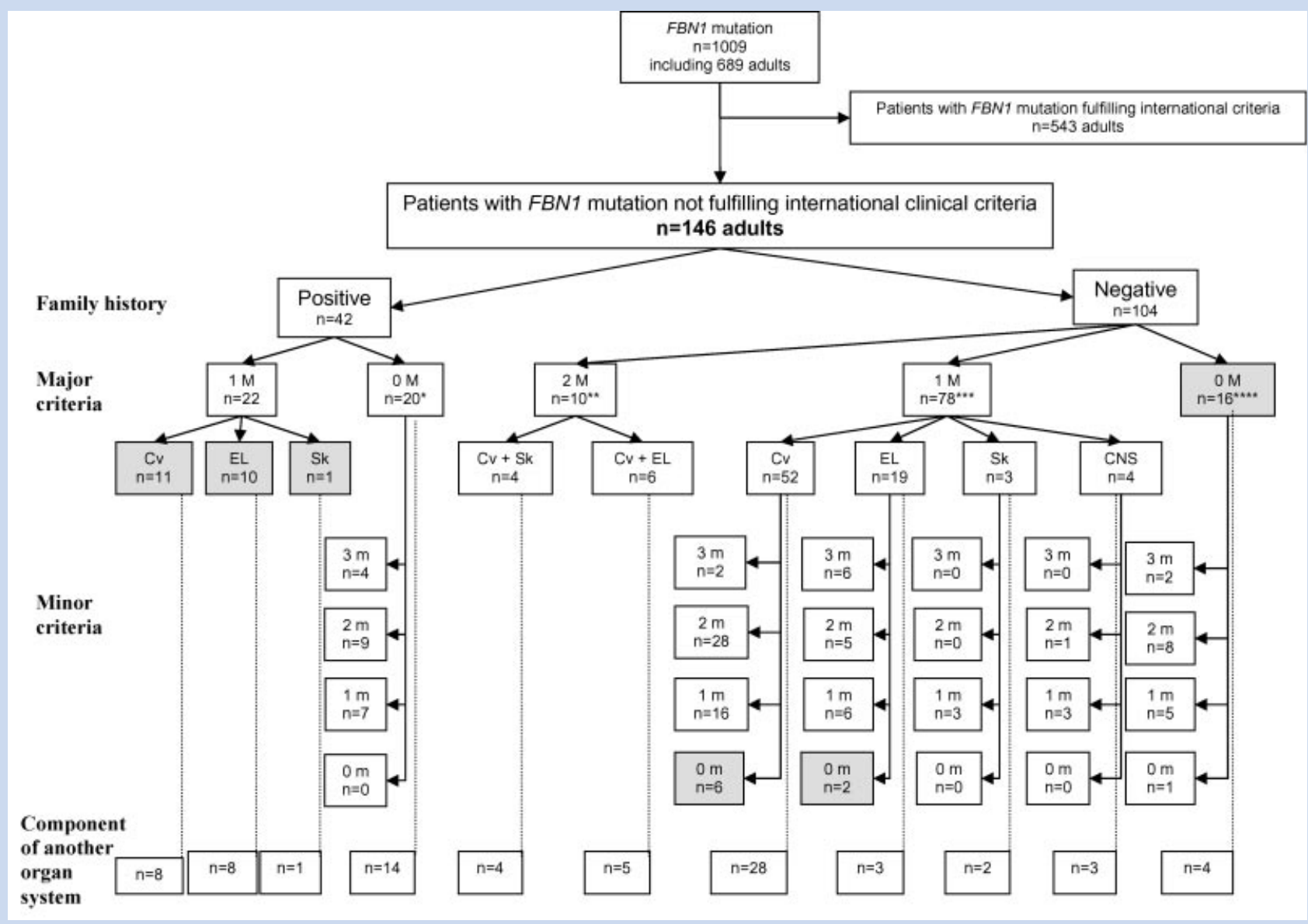

FIG. 1. Distribution of organ system involvement in 146 patients not fulfilling international clinical criteria for the diagnosis of Marfan syndrome. Besides clinical criteria, patients are classified with or without a positive family history. Gray squares represent the patients with major clinical criterion only or with minor criteria only. The words criteria, minor and major criteria, organ system component are strictly used throughout the article as defined in the article by De Paepe et al. [1996] that define the internationally recognized Ghent diagnostic criteria for MFS. The presence of a component of one organ system defines a clinical feature insufficient alone to make a minor criterion. Cv, cardiovascular system; CNS, central nervous system; EL, ectopia lentis; M, major; m, minor; $n$, number; Sk, skin system, *Six patients were checked for dural ectasia and 5 for protrusion acetabuli, ${ }^{* *} 4$ patients were checked for dural ectasia and 10 for protrusion acetabuli, ${ }^{* * *} 2$ patients were checked for dural ectasia and none for protrusion acetabuli, ****14 patients were checked for dural ectasia and 26 for protrusion acetabuli, ${ }^{* * * * *} 3$ patients were checked for dural ectasia and 3 for protrusion acetabuli.

relatives of 3 adult propositi with isolated AAD was available; 9/11 had AAD which was isolated in 7 of them.

\section{DISCUSSION}

FBN1 mutations have been associated with a broad spectrum of phenotypes, ranging from lethal neonatal MFS to single connectivetissue manifestations, such as isolated EL [Robinson et al., 2002]. From a cohort of 146 adult patients with incomplete clinical international criteria out of a series of 1,009 patients carrying a FBN1 mutation (689 adults), we previously showed that the majority of patients had 2 major criteria or one major and one to 3 minor criteria $(122 / 146,84 \%$ of patients with incomplete international criteria) [Faivre et al., 2008]. The type and location of mutations were not significantly different from the distribution of mutations in the overall series of FBN1 patients. The age at diagnosis in the group of patients with incomplete clinical international criteria was not statistically different from the Ghent positive patients, which does not argue in favor of an age dependent penetrance effect.

In this article, we showed that mild presentations, including an isolated major clinical criterion or one to three minor criteria, are rare when strictly applying the Ghent nosology. However, the frequency of such phenotypes may be underestimated since these patients are not routinely screened for FBN1 mutations. The data reported in this article indicates that mild phenotypes are rare in FBN1 mutations, suggesting that the mutation detection rate in this category of patients is low and should be performed on a research basis only.

The existence of isolated EL or isolated AAD as a genuine entity is subject to discussion: (i) some individuals of the family first described with isolated EL [Kainulainen et al., 1994] developed 
TABLE I. Location and Type of Mutation in the Subgroups of Adult Probands With Isolated Major Criteria (With or Without the Presence of At Least One Minor Criteria] or With no Major Criteria, as Compared With the Cohort of Patients With Other Type I Fibrillinopathies and the Overall Population of Probands Heterozygous for a FBN1 Mutation

Isolated $E L(n=12)$

$\mathrm{EL}+$ at least 1 minor criteria $(\mathrm{n}=27)$

Isolated $\operatorname{AAD}(n=17)$

$\mathrm{AAD}+$ at least 1 minor criteria $(\mathrm{n}=60)$

0 major criteria $(n=16)$

Other type I fibrillinopathies $(n=146)$

Overall ( $n=1,009$, Faivre et al., 2007)

\section{Exons 24-32}

n
1
2
4
12
4
25
198

$\%$

8

7

24

20

25

17

20 $\mathbf{5}^{\prime}$

\begin{tabular}{cc}
\multicolumn{2}{c}{$\mathbf{5}^{\prime}$} \\
\hline $\mathbf{n}$ & $\%$ \\
6 & 50 \\
11 & 38 \\
7 & 41 \\
19 & 32 \\
5 & 31 \\
44 & 30 \\
291 & 29
\end{tabular}

\begin{tabular}{cc}
\multicolumn{2}{c}{ PTC } \\
\hline $\mathbf{n}$ & $\%$ \\
0 & 0 \\
4 & 14 \\
5 & 29 \\
25 & 42 \\
6 & 38 \\
47 & 32 \\
319 & 32
\end{tabular}

\begin{tabular}{cc}
\multicolumn{2}{c}{ MS Cys } \\
\hline $\mathbf{n}$ & $\%$ \\
8 & 67 \\
17 & 59 \\
3 & 18 \\
10 & 17 \\
1 & 6 \\
35 & 24 \\
348 & 34
\end{tabular}

$5^{\prime}$ : mutation at the $5^{\prime}$ end of the FBN1 gene (exons 1-21 inclusive); PTC: premature truncation; MS Cys: missense mutation involving a cysteine; n: number.

late-onset cardiovascular features [Black et al., 1998]; (ii) the recurrent c. $718 \mathrm{C}>\mathrm{T}$ and c. $2272 \mathrm{~T}>\mathrm{C}$ mutations, first described in association with isolated EL, were found to be associated with aortic dilatation and a classical MFS phenotype in other patients [Loeys et al., 2001]; (iii) we show in this study that relatives of an adult propositus with isolated EL or AAD do not all present with the same phenotype. Nevertheless, although varying degrees of expression were found among family members, phenotypes seemed to be incomplete more often than expected by chance. This could also be due to familial clustering of a milder phenotype secondary to modifier genes, rather than an association with a hypomorphic FBN1 mutation. Of note, these considerations depend on the definition used as well as the age of inclusion. Indeed, in some publications, the presence of minor skeletal or skin components, and even minor cardiac features, are accepted in the definition of patients with an EL phenotype for example [Comeglio et al., 2002; Adès et al., 2004]. Such descriptions in childhood have led to misdiagnosis in the past [Kainulainen et al., 1994; Black et al., 1998]. We took advantage of the availability of a large series of patients to accept only strict definitions and to consider adults only since a number of features of MFS develop with age to minimize the risk for misclassification. For these reasons, and the similar age of the cohorts of patients fulfilling or not international criteria, we believe that there is a continuum between classical MFS and isolated major criterion of one clinical system. Given the high number of patients with some components of the skeletal system of the Ghent nosology, careful clinical evaluation of a propositus with an isolated major criterion and their family members is mandatory before starting FBN1 gene mutation studies. This is of particular importance in patients with isolated $\mathrm{AAD}$, considering the increasing number of other genes with mutations known to produce familial thoracic aneurysms [Milewicz et al., 1996; Loeys et al., 2005; Pannu et al., 2005; Zhu et al., 2006; Guo et al., 2007].

The presence of patients in our series without a major criterion is rare (only 16 patients who had 0-3 minor organ system criteria, $1.5 \%$ of the general cohort). The presence of a minor criterion in the skeletal system according to the Ghent nosology is often the criterion that led to a FBN1 molecular analysis on a research basis.
The recent description of a family with isolated minor skeletal features and incomplete penetrance is a striking example of the extremely mild to absent phenotype associated with some FBN1 mutations [Buoni et al., 2004], leading to difficulties in genetic counseling and follow-up. The addition of dural ectasia screening, if not previously performed during clinical evaluation of patients and relatives, could help determine the need for aortic follow-up [Rose et al., 2000]. Only 27/146 (18\%) of our patients were screened for dural ectasia although they presented an incomplete phenotype.

These atypical presentations raise the question of when to call a phenotype in someone MFS and when not. Patients carrying a FBN1 mutation does not implicate that they have MFS. Indeed, the presence of a FBN1 mutation was not considered as equal to having MFS in the international criteria for MFS [De Paepe et al., 1996]. For example, a patient presenting an isolated EL or an isolated skeletal phenotype and a pathogenic FBN1 mutation cannot be classified as having MFS, but they have a type I fibrillinopathy. It remains justified to keep separate these entities, since, although cardiovascular manifestations can arise in all presentations, complications may arise in puberty or early adulthood in a life-threatening way in MFS, while less serious cardiovascular presentations can occur later in life in isolated EL for example [Lönnqvist et al., 1994; Hennekam, 2007].

We tried to determine if such mild phenotypes are associated with a specific type or location of FBN1 mutation, but statistical power was insufficient. However, no PTC mutations were found in association with isolated EL, which correlate with previous findings [Comeglio et al., 2002; Faivre et al., 2007]. Also, FBN1 mutations in patients with “isolated" EL are preferentially located in the $5^{\prime}$ region of the gene and mutations in exons 24-32 are less frequent than expected. Missense mutations involving a cysteine appeared underrepresented in patients with isolated AAD when compared to "isolated" EL, giving further emphasis to the important role of correct cysteine localization in the structural integrity of suspensory ligaments of the lens [Nemet et al., 2006]. The same tendency was found for patients with EL and at least one minor criterion of another organ system. 
In conclusion, using Ghent nosology, patients with only one major clinical criterion and patients with only one to three minor criteria do exist but represent only $5 \%$ of the adult cohort of all patients with FBN1 mutation.

\section{ACKNOWLEDGMENTS}

The authors thank HC. Dietz (Baltimore, USA), I. Kaitila (Helsinki, Finland), P. Khau Van Kien (Montpellier, France), H. Plauchu (Lyon, France), D. Halliday (Oxford, UK), S. Davies (Cardiff, Wales) and T. Uyeda (Irosaki, Japan) for their participation in the study. This work was supported by grants from the French Ministry of Health, GIS-Maladies Rares and ANR-Maladies Rares 2005 (GJ and $\mathrm{CB}$ ). $\mathrm{BC}$ and $\mathrm{BL}$ are a research fellow and a senior clinical investigator of the Fund for Scientific Research-Flanders, respectively. AC, AK and PC thank the Marfan Trust and Bluff Field Charitable Trust for support.

\section{REFERENCES}

Adès LC, Sreetharan D, Onikul E, Stockton V, Watson KC, Holman KJ. 2002. Segregation of a novel FBN1 gene mutation, G1796E, with kyphoscoliosis and radiographic evidence of vertebral dysplasia in three generations. Am J Med Genet 109:261-270.

Adès LC, Holman KJ, Brett MS, Edwards MJ, Bennetts B. 2004. Ectopia lentis phenotypes and the FBN1 gene. Am J Med Genet Part A 126A:284-289.

Beroud C, Hamroun D, Collod-Beroud G, Boileau C, Soussi T, Claustres M. 2005. UMD (Universal Mutation Database): 2005 update. Hum Mutat 26:184-191.

Black C, Withers AP, Gray JR, Bridges AB, Craig A, Baty DU, Boxer M. 1998. Correlation of a recurrent FBN1 mutation (R122C) with an atypical familial Marfan syndrome phenotype. Hum Mutat Supp 1:S198-S200.

Boileau C, Jondeau G, Mizuguchi T, Matsumoto N. 2005. Molecular genetics of Marfan syndrome. Curr Opin Cardiol 20:194-200.

Buoni S, Zannolli R, Macucci F, Ansaldi S, Grasso M, Arbustini E, Fois A. 2004. The FBN1 (R2726W) mutation is not fully penetrant. Ann Hum Genet 68:633-638.

Collod-Beroud G, Le Bourdelles S, Ades L, Ala-Kokko L, Booms P, Boxer M, Child A, Comeglio P, De Paepe A, Hyland JC, Holman K, Kaitila I, Loeys B, Matyas G, Nuytinck L, Peltonen L, Rantamaki T, Robinson P, Steinmann B, Junien C, Beroud C, Boileau C. 2003. Update of the UMDFBN1 mutation database and creation of an FBN1 polymorphism database. Hum Mutat 22:199-208.

Comeglio P, Evans AL, Brice G, Cooling RJ, Child AH. 2002. Identification of FBN1 gene mutations in patients with ectopia lentis and marfanoid habitus. Br J Ophthalmol 86:1359-1362.

De Paepe A, Devereux RB, Dietz HC, Hennekam RC, Pyeritz RE. 1996. Revised diagnostic criteria for the Marfan syndrome. Am J Med Genet 62:417-426.

Dietz HC, Pyeritz RE. 1995. Mutations in the human gene for fibrillin-1 (FBN1) in the Marfan syndrome and related disorders. Hum Mol Genet 4:1799-1809.

Dietz HC, Cutting GR, Pyeritz RE, Maslen CL, Sakai LY, Corson GM, Puffenberger EG, Hamosh A, Nanthakumar EJ, Curristin SM, Stetten G, Meyers DA, Francomano CA. 1991. Marfan syndrome caused by a recurrent de novo missense mutation in the fibrillin gene. Nature 352:337-339.
Downing A, Knott V, Werner J, Cardy C, Campbell ID, Handford PA. 1996. Solution structure of a pair of calcium-binding epidermal growth factorlike domains: Implications for the Marfan syndrome and other genetic disorders. Cell 85:597-605.

Faivre L, Collod-Beroud G, Loeys BL, Child A, Binquet C, Gautier E, Callewaert B, Arbustini E, Mayer K, Arslan-Kirchner M, Kiotsekoglou A, Comeglio P, Marziliano N, Dietz HC, Halliday D, Beroud C, BonithonKopp C, Claustres M, Muti C, Plauchu H, Robinson PN, Adès LC, Biggin A, Benetts B, Brett M, Holman KJ, De Baecker J, Coucke P, Francke U, De Paepe A, Jondeau G, Boileau C. 2007. Effect of mutation type and location on clinical outcome in 1013 probands with Marfan syndrome or related phenotypes with FBN1 mutations: An international study. Am J Hum Genet 81:454-466.

Faivre L, Collod-Beroud G, Child A, Callewaert B, Loeys BL, Binquet C, Gautier E, Arbustini E, Mayer K, Arslan-Kirchner M, Stheneur C, Kiotsekoglou A, Comeglio P, Marziliano N, Halliday D, Beroud C, Bonithon-Kopp C, Claustres M, Plauchu H, Robinson PN, Adès L, De Backer J, Coucke P, Francke U, De Paepe A, Boileau C, Jondeau G. 2008. Contribution of molecular screening in diagnosing Marfan syndrome and type I fibrillinopathies: An international study of 1009 probands. J Med Genet 45:384-390.

Francke U, Berg MA, Tynan K, Brenn T, Liu W, Aoyama T, Gasner C, Miller DC, Furthmayr H. 1995. A Gly1127Ser mutation in an EGF-like domain of the fibrillin-1 gene is a risk factor for ascending aortic aneurysm and dissection. Am J Hum Genet 56: $1287-1296$.

Furthmayr H, Francke U. 1997. Ascending aortic aneurysm with or without features of Marfan syndrome and other fibrillinopathies: New insights. Semin Thorac Cardiovasc Surg 9:191-205.

Guo DC, Pannu H, Tran-Fadulu V, Papke CL, Yu RK, Avidan N, Bourgeois S, Estrera AL, Safi HJ, Sparks E, Amor D, Ades L, McConnell V, Willoughby CE, Abuelo D, Willing M, Lewis RA, Kim DH, Scherer S, Tung PP, Ahn C, Buja LM, Raman CS, Shete SS, Milewicz DM. 2007. Mutations in smooth muscle alpha-actin (ACTA2) lead to thoracic aortic aneurysms and dissections. Nat Genet 39:1488-1493.

Hayward C, Porteous ME, Brock DJ. 1994. A novel mutation in the fibrillin gene (FBN1) in familial arachnodactyly. Mol Cell Probes 8:325-327.

Henikoff S, Henikoff JG. 1992. Amino acid substitution matrices from protein blocks. Proc Natl Acad Sci USA 89:10915-10919.

Hennekam RCM. 2007. What to call a syndrome. Am J Med Genet Part A 143A:1021-1024.

Judge DP, Dietz HC. 2005. Marfan's syndrome. Lancet 366:19651976.

Kainulainen K, Karttunen L, Puhakka L, Sakai L, Peltonen L. 1994. Mutations in the fibrillin gene responsible for dominant ectopia lentis and neonatal Marfan syndrome. Nat Genet 6:64-69.

Loeys B, Nuytinck L, Delvaux I, De Bie S, De Paepe A. 2001. Genotype and phenotype analysis of 171 patients referred for molecular study of the fibrillin-1 gene FBN1 because of suspected Marfan syndrome. Arch Intern Med 161:2447-2454.

Loeys BL, Chen J, Neptune ER, Judge DP, Podowski M, Holm T, Meyers J, Leitch CC, Katsanis N, Sharifi N, Xu FL, Myers LA, Spevak PJ, Cameron DE, De Backer J, Hellemans J, Chen Y, Davis EC, Webb CL, Kress W, Coucke P, Rifkin DB, De Paepe AM, Dietz HC. 2005. A syndrome of altered cardiovascular, craniofacial, neurocognitive and skeletal development caused by mutations in TGFBR1 or TGFBR2. Nat Genet 37: $275-281$.

Lönnqvist L, Child A, Kainulainen K, Davidson R, Puhakka L, Peltonen L. 1994. A novel mutation of the fibrillin gene causing ectopia lentis. Genomics 19:573-576. 
Milewicz DM, Grossfield J, Cao SN, Kielty C, Covitz W, Jewett T. 1995. A mutation in FBN1 disrupts profibrillin processing and results in isolated skeletal features of the Marfan syndrome. J Clin Invest 95:2373-2378.

Milewicz DM, Michael K, Fisher N, Coselli JS, Markello T, Biddinger A. 1996. Fibrillin-1 (FBN1) mutations in patients with thoracic aortic aneurysms. Circulation 94:2708-2711.

Nemet AY, Assia EI, Apple DJ, Barequet IS. 2006. Current concepts of ocular manifestations in Marfan syndrome. Surv Ophthalmol 51: 561-575.

Ng PC, Henikoff S. 2001. Predicting deleterious amino acid substitutions. Genome Res 11:863-874.

Ng PC, Henikoff S. 2003. SIFT: Predicting amino acid changes that affect protein function. Nucleic Acids Res 31:3812-3814.

Pannu H, Fadulu VT, Chang J, Lafont A, Hasham SN, Sparks E, Giampietro PF, Zaleski C, Estrera AL, Safi HJ, Shete S, Willing MC, Raman CS, Milewicz DM. 2005. Mutations in transforming growth factor-beta receptor type II cause familial thoracic aortic aneurysms and dissections. Circulation 112:513-520.

Pyeritz RE. 1993. Marfan syndrome: Current and future clinical and genetic management of cardiovascular manifestations. Semin Thorac Cardiovasc Surg 5:11-16.
Robinson PN, Booms P, Katzke S, Ladewig M, Neumann L, Palz M, Pregla R, Tiecke F, Rosenberg T. 2002. Mutations of FBN1 and genotypephenotype correlations in Marfan syndrome and related fibrillinopathies. Hum Mutat 20:153-161.

Robinson PN, Arteaga-Solis E, Baldock C, Collod-Beroud G, Booms P, De Paepe A, Dietz HC, Guo G, Handford PA, Judge DP, Kielty CM, Loeys B, Milewicz DM, Ney A, Ramirez F, Reinhardt DP, Tiedemann K, Whiteman P, Godfrey M. 2006. The molecular genetics of Marfan syndrome and related disorders. J Med Genet 43:769-787.

Rose PS, Levy HP, Ahn NU, Sponseller PD, Magyari T, Davis J, Francomano CA. 2000. A comparison of the Berlin and Ghent nosologies and the influence of dural ectasia in the diagnosis of Marfan syndrome. Genet Med 2:278-282.

Shapiro MB, Senapathy P. 1987. RNA splice junctions of different classes of eukaryotes: Sequence statistics and functional implications in gene expression. Nucleic Acids Res 15:7155-7174.

Zhu L, Vranckx R, Khau Van Kien P, Lalande A, Boisset N, Mathieu F, Wegman M, Glancy L, Gasc JM, Brunotte F, Bruneval P, Wolf JE, Michel JB, Jeunemaitre X. 2006. Mutations in myosin heavy chain 11 cause a syndrome associating thoracic aortic aneurysm/aortic dissection and patent ductus arteriosus. Nat Genet 38:343-349. 